\title{
MODELOS IDENTITÁRIOS EM AMANHÃ, NUMA BOA DE FAÏZA GUÈNE ${ }^{1}$
}

Dionei Mathias

Resumo: O romance Amanhã, numa boa, escrito por Faïza Guène e publicado em 2004 apresenta história de Doria, filha de pais marroquinos e que vive no subúrbio da capital francesa. Numa situação econômica e social vulnerável, a jovem protagonista enfrenta diversos obstáculos no seu caminho de integração à sociedade francesa e, sobretudo, de construção da própria narrativa de identidade. Nesse contexto, as diferentes personagens-modelo têm um impacto substancial em sua identidade, pois contribuem para a revisão e diferenciação da visão de mundo de Doria. Em grande parte, essas personagens contribuem para a reflexão sobre a posição da mulher na intersecção com a imigração, mostrando diferentes formas de empoderamento e obtenção de voz para a construção de uma identidade em consonância com seus anseios. Nesse sentido, este artigo deseja discutir essas personagens-modelo e sua importância para a construção de identidade da protagonista, focando em personagens distantes, isto é, que não têm contato direto com ela, e personagens próximas, que circulam no mesmo espaço social. Palavras-Chave: Faïza Guène. Amanhã, numa boa. Modelos identitários.

Abstract: The novel Kiffe kiffe demain, written by Faïza Guène and published in 2004, presents the story of Doria, daughter to Moroccan parents and based in the French capital's suburb. Finding herself in a vulnerable economic and social condition, the young main character faces several obstacles in her way to integration into French society and, above all, to the formation of her own identity. In this context, the different model-characters have a substantial impact on her identity, since they contribute to the revision and differentiation of Doria's worldview. To a great extent, these characters contribute to her reflection about the position of women in the intersection with immigration, showing different ways of empowerment and articulation of her voice, to form an identity in consonance with her needs. In this sense, this article wishes to discuss these model characters and their importance for the main character's identity construction, focusing on

1 Título em língua estrangeira: "Identity models in Faïza Guène’s Kiffe, kiffe demain". 
distant characters, i.e., those without any direct contact with her, and close characters, i.e., those moving in the same social space.

Keywords: Faïza Guène. Kiffe kiffe demain. Identity models.

\section{INTRODUÇÃO}

Todo processo de socialização ensina ao indivíduo como deve se apropriar da realidade e como deve conceber seu projeto de vida. Isso já tem início na primeira microestrutura social, que é a família. Ao imitar as ações da mãe, do pai e dos outros membros da família, a criança começa a enxergar o mundo e a idear modos de se representar, seguindo os modelos recebidos. É nesse primeiro círculo que a criança também experimenta de forma lúdica com formas de representação e inovação das imagens do si (HERMANNS, 2001, p. 243). Ao estender seu círculo de interação, também aumenta a oferta de modelos, com suas formas de se posicionar no mundo, a partir de práticas de comunicação, organização do pensamento, concretização de ação e comportamento e de configurações afetivas.

O contato com modelos identitários obviamente depende em grande medida das narrativas que circulam num determinado espaço social (MATHIAS, 2020a). Para a experiência feminina, contudo, essas ofertas narrativas, em grande parte, estiveram atreladas a visões de mundo patriarcais, como aponta o estudo de Carreira: 
Às mulheres foi negada, historicamente, a sua genealogia feminina. A sua identidade foi construída em associações ditadas pelo patriarcado. A imposição do sobrenome do pai, do qual a mulher só poderia abrir mão na condição de substituição pelo sobrenome do marido, é símbolo de uma relação de pertencimento que atravessou a história. Genealogicamente, a identidade feminina sempre foi construída em relação a alguém, que era, historicamente, masculino, e essa dependência gerou uma afasia cultural. (2010, p. 47)

Nesse contexto histórico, as reflexões sobre a escrita da mulher, em algum momento, se voltam para a necessidade de problematizar os modelos disponíveis e assim pensar sobre construções identitárias que se afastam dos moldes ditados pelo pensamento patriarcal. Esse movimento está atrelado a um esforço de identificar na escrita de mulheres outras genealogias e histórias, a fim de reconhecer seu "espírito criativo" (2016, p. 133), como mostra Rapucci em seu estudo sobre Conceição Evaristo e a importância de Alice Walker.

O romance Kiffe kiffe demain de 2004, traduzido para o português brasileiro com o título Amanhã, numa boa, por Luciana Persice Nogueira, em 2006, se junta a esse esforço, tendo como foco a experiência feminina na confluência com a experiência de imigração. Nesse horizonte, a jovem autora Faïza Guène expõe excertos da realidade francesa, a partir da 
perspectiva de uma adolescente de pais argelinos, nascida na França e que vive no subúrbio da capital. Num tom jocoso e subversivo, numa versão contemporânea do romance pícaro, a voz narrativa autodiegética relata suas dificuldades, diante do pai que abandona a família, da alteridade cultural, da pobreza num país rico, das insensibilidades do mundo escolar e da figura materna, com seus desafios no mercado de trabalho.

Não diferente de uma jovem do grupo dominante, também essa protagonista muçulmana e de pais imigrantes, pertencente à segunda geração, procura por modelos identitários, não somente para entender a realidade e aprender a negociar seu lugar no mundo, mas sobretudo para estimular a imaginação do futuro. Nesse contexto, Guène se inscreve numa produção discursiva voltada para a representação de aspectos da experiência de imigração, uma experiência perpassada por tensões e incertezas:

Os deslocamentos espacial ou cultural dos sujeitos não se fazem, contudo, sem a articulação entre memória e identidade, e a definição identitária depende da percepção, da alteridade e da diferença, implicando, queira-se ou não, ranhuras, fissuras, fraturas, rupturas ou, mesmo, perdas. (MELO; CARREIRA, 2019, p. 1)

De certa forma, ela problematiza essas "fissuras" na busca por modelos. Nesse sentido, seu romance empreende um 
trabalho de revisão da literatura francesa contemporânea ao contribuir com a criação de um universo ficcional, onde mulheres migrantes têm voz (ALBERT, 2005). Ao mesmo tempo, por meio da ironia e do humor (HARGREAVES, 2011, p. 41), Guène diferencia as imagens da periferia de Paris que circulam na produção discursiva hegemônica. Com efeito, sua escrita se insere no esforço de oferecer outras genealogias e, com isso, outros modelos para pensar posicionamentos no espaço social. Esses modelos têm um impacto substancial nas modalidades de narração da identidade, por exemplo nas intersecções básicas de gênero, raça, classe, sexualidade ou cultura (HARGREAVES, 2001, p. 7). As tessituras de identidade desenvolvidas pelo indivíduo, com base nos modelos que adota como norte, tomam forma a partir desses vetores, especialmente diante do modo como são vividos e concretizados por atores sociais que têm significância afetiva para o sujeito (KEUPP et al., 2002).

Nesse horizonte, o modo como outras mulheres vivem sua identidade de gênero dentro do grupo ao qual pertence a protagonista tem um papel central, uma vez que ele traça o caminho a ser enveredado. Posteriormente, essa primeira tessitura pode ser revidada e reformulada, com base nas negociações com outros grupos. Cross e Madson escrevem: 
Em casas, escolas, mercados e outros ambientes sociais, os indivíduos são informados de quem são, quem devem ser e como criar uma identidade. Os indivíduos constroem ativamente um si (self) ao participar de seus ambientes sociais; o si, por sua vez, facilita o envolvimento e a adaptação a esses ambientes. Em suma, o si negocia a interação entre a pessoa e a sociedade. No entanto, os pontos de vista sobre a natureza do si variam substancialmente em todo o mundo, resultando em modelos muito diferentes do $\mathrm{si}^{2}$. $(1997$, p. 6)

Nessa busca por modelos na ideação de papéis de gênero, proximidade e distância de atores sociais que inspiram emulação se revela de grande importância. Assim, os modelos para a identidade a ser construída podem ser atores sociais próximos, que fazem parte do círculo social do indivíduo, ou mais distantes, sem interações diretas. Nesse contexto, o primeiro grupo se revela especialmente interessante, pois além de servir como base para a própria concretização existencial, a interação com esses modelos se transforma em algum tipo de capital social.

Isto é, trata-se de atores sociais que, de alguma forma, dedicam atenção e investem afetos àqueles a quem servem

2 "In homes, schools, marketplaces, and other social environments, individuals are told who they are, who they should be, and how to create an identity. Individuals actively construct a self as they participate in their social environments; the self, in turn, facilitates engagement in and adaptation to these environments. In short, the self negotiates the interaction between the person and society. However, viewpoints about the nature of the self vary substantially around the world, resulting in very different models of the self" (CROSS/MADSON, 1997, p. 6, tradução nossa). 
de modelo. Esse investimento afetivo talvez seja ainda mais importante que a narrativa identitária cujo conteúdo se torna o objetivo de emulação, pois no eixo afetivo parece residir o maior potencial para despertar e apoiar processos de transformação. Isto é, o interlocutor que está disposto a investir atenção e afetos, em maior ou menor grau, também vai dedicar sua energia cognitiva, a fim de que o sujeito para quem serve de modelo alcance seus objetivos ou, ao menos, uma base que lhe permita trilhar um caminho em consonância com seus desejos.

No universo diegético do romance de Faïza Guène, o mais importante modelo de identidade para a jovem protagonista é a própria mãe, imigrante de origem argelina. Esta, além de ser analfabeta e ter sido abandonada pelo marido, desempenha um trabalho que a oprime. Todos esses eixos parecem ser negativos, especialmente numa sociedade de mérito e marcada pelo imperativo do êxito. A figura materna, contudo, representa o cerne afetivo da protagonista e cada vitória no sentido de adquirir um maior grau de autonomia é motivo de comemoração para filha. Nesse relacionamento, há uma grande sintonia, caracterizada pelo respeito e é justamente no modo como a mãe investe e administra seus afetos que reside o modelo que desperta a admiração da filha, conquistando seu respeito e seu desejo de emulação. 
Além da mãe, como uma das personagens centrais do romance, cujo papel no universo da filha já foi discutido por Mathias (2020b), há uma série de personagens secundárias que circulam no contexto do subúrbio e cujas histórias se entrelaçam com a da protagonista. Nessa interseção de narrativas de identidade, seus interlocutores negociam suas identidades e acabam se transformando em modelos para a jovem voz narrativa. Como escreve Ahonen:

Nessa história, mulheres não ocupam o papel de vítimas, pelo contrário, são fortes e independentes. Mulheres não se sentem inseguras no romance, tampouco a periferia (banlieue) é retratada como perigosa para elas. Com efeito, alguns eventos são vistos numa luz claramente irônica ou representam histórias de sobrevivência, criando uma sensação de esperança. Ao sugerir que é possível influenciar o próprio futuro, elas são empoderadoras. As mulheres no romance assumem o controle de seu próprio futuro ${ }^{3}$. (2016, p. 174)

A partir desse horizonte, a discussão das personagens secundárias e de seu papel de modelo forma o foco deste artigo, buscando refletir como as ações e os comportamentos impactam na visão de mundo da protagonista Doria,

3 "Women do not occupy the role of a victim in this story, but are strong and independent. Women do not feel insecure in the novel, nor is the banlieue portrayed as dangerous for them. In fact, some events are seen in a clearly ironic light or are stories of survival, creating a sense of hope. In suggesting that one can influence one's future, they are empowering. The women in the novel take control of their own future" (AHONEN, 2016, p. 174). 
especialmente no que diz respeito a sua concepção de gênero. Todas as personagens secundárias a serem discutidas aqui são personagens femininas com uma história de fluxo migratório. Todas elas são confrontadas com expectativas patriarcais de comportamento, o que desencadeia nelas alguma forma de resistência. Doria relata e discute essas experiências, servindo-se delas como modelo para a própria construção de identidade.

\section{MODELOS DISTANTES}

As personagens secundárias com as quais a protagonista interage são diversas. Algumas pertencem ao círculo de interações da mãe, outras fazem parte do círculo de Doria, a protagonista, e um último grupo, por fim, é formado por personagens que têm uma história cultural pautada por fluxos migratórios, mas que não apresentam qualquer interação direta com a voz narrativa. A esse último grupo, pertence o episódio de Samra, uma jovem muçulmana:

Voltaram a falar da Samra no Conjunto. Samra é a prisioneira que morava no meu prédio, o pai e o irmão tendo forçado a barra a tal ponto que ela teve que se mandar. Há poucos dias, alguém a viu não muito longe, ou, talvez, muito longe não lembro. [...] Pelo que todo mundo anda falando ele é um toubab, quer dizer, um branco, branquelo, um camembert, um aspirina... Por isso, o 
irmão da Samra, aquele que tem uma luva de boxe no lugar do cérebro, tá a fim de esfolar ele vivo, e olha que o único pecado que ele cometeu na vida foi dar um pouco de amor à irmã do infeliz. Pra mim, eles devem ter mudado pra um lugar bem longe para poderem viver em paz. Escondidos, igual a dois fugitivos, culpados por um troço normal. Às vezes, penso cá comigo que certas pessoas têm que lutar por tudo na vida. Até mesmo pra poder amar é uma batalha. (GUÈNE, 2006, p. 122-123) ${ }^{4}$

O conjunto habitacional fica no subúrbio da capital francesa e é o lugar de residência da protagonista, acolhendo além dela muitas outras famílias de imigrantes. Trata-se de um espaço, em parte, deteriorado estruturalmente, refletindo a fragilidade do contexto social das famílias que vivem por lá. Como jovem mulher, muçulmana e com pais de origem estrangeira, Samra apresenta uma série de características que possibilitam uma identificação por parte de Doria. A narrativa em si, que estabelece a plataforma de contato entre essas duas realidades, na verdade, não contém elementos de intersecção propriamente. Samra se

\footnotetext{
4 “Des nouvelles de Samra ont flotté dans la cité. Samra, c'est la prisonnière qu'habitait dans mon immeuble et que le frère et le père ont poussée à bout jusqu'à ce qu'elle se tire. On l'aurait aperçue, il y a quelques jours, pas trop loin, ou alors très loin, je sais plus. [...] D'après ce que tout le monde dit, c'est un toubab, enfin un Blanc, un camembert, une aspirine quoi... Alors le frère de Samra, celui qui a un gant de boxe à la place du cerveau, il veut sa peau au pauvre mec, alors que le seul crime qu'il ait jamais commis c'est d'avoir donné un peu d'amour à sa sœur. À mon avis, ils ont dû déménager et s'installer plus loin pour qu'on leur fiche la paix. En planque, comme des fugitifs, coupables d'un truc normal. Parfois je me dis qu'il y a des gens qui doivent se battre pour toute chose. Même pour aimer c'est la lutte" (GUÈNE, 2011, p. 85).
} 
apaixona por um homem pertencente ao grupo dominante, por alguém, portanto, que apresenta um histórico de pertencimento cultural e racial diferente das experiências da protagonista. Doria, por sua vez, fará suas primeiras experiências amorosas ao longo da narrativa, nesse caso, com um rapaz que pertence ao grupo de famílias com histórico de imigração, oriundas do Maghreb. Enquanto Samra se vê confrontada com uma série de conflitos relacionados com sua escolha afetiva, Doria não os tem no contexto de sua família.

Mais importante que o relacionamento em si é fato de que a narrativa, neste caso, gira em torno da questão da autonomia feminina, uma questão recorrente na literatura oriunda de fluxos migratórios. Com base no exemplo da narrativa de Samra, Doria começa a tecer suas próprias narrativas de realidade. Ela constata, nesse relato, que o irmão, em outro episódio, também o pai tomam para si o direito de decisão sobre a vida da jovem Samra, impedindo que concretize sua existência, em consonância com sua imaginação de futuro. Em nome de uma socialização cultural, pautada pelo princípio da honra, sua narrativa é alvo de perseguição, com tentativas de silenciamento.

Doria não se limita a replicar esse relato em sua própria narrativa, ela também o analisa, revelando sua visão de 
mundo e os valores, aos quais atribui importância. Nisso, ela claramente se solidariza com o destino de Samra e com a forma como ela opta por concretizar sua existência. Isto é, no lugar de internalizar e reproduzir a visão de mundo herdada de uma socialização cultural (patriarcal) que atribui o monopólio da decisão ao homem, Doria começa a se identificar com modelos que optam por não renunciar àquilo que lhes é importante e que lutam por seus direitos, a despeito da imposição de restrições e da violência.

Esse modelo de identidade não está relacionado a elementos concretos da existência de Doria, pois ela não sofre com esse tipo de violência, mas ele oferece um modo de enxergar a vida, num contexto em que sua socialização cultural primária difere da cultura dominante, no espaço em que circula. Ela aprende, por meio desse exemplo, que outras mulheres do seu contexto social enfrentam grandes obstáculos, ao construírem suas identidades, ao mesmo também, se inspira na coragem, com a qual vão em busca daquilo que lhes é importante. Nesse sentido, ela deriva conhecimentos desse modelo, especialmente no que diz respeito a papéis de gênero, e os transfere para sua realidade pessoal.

Num outro episódio que ilustra o impacto de modelos distantes, o fator que refreia a liberdade de elaboração da 
narrativa de identidade vem da comunidade. Se no primeiro exemplo o ponto de partida do aparato de vigilância tinha sua origem na família, neste segundo ele provém da comunidade:

Até o dia em que os pais encontraram uma carta anônima na caixa do correio. Ela foi publicada na íntegra no jornal Entre Amigos, junto com o depoimento da tal menina [...] No Entre Amigos, ela contou que, depois dessa, resolveu fugir de casa. Hoje, ela vive sozinha, e não tem praticamente mais nenhum contato com os pais. Mas ela entrou pra Comédie-Française, e conseguiu viver a sua paixão. Ela venceu, apesar dos pesares. (GUÈNE, 2006, p. 155-156) ${ }^{5}$

No exemplo dessa menina, os pais lhe dão muito mais liberdade, num primeiro momento, do que no primeiro caso. Assim, eles lhe permitem participar de grupos de teatro, viajar pela França para realizar suas apresentações e, de certo modo, adotar práticas predominantes no espaço cultural francês. Com boas notas na escola e podendo ter contato com diversas formas da expressão artística, a menina apresenta um potencial muito maior de tecer uma narrativa de identidade pautada por suas escolhas próprias. Isso tudo muda com a chegada da carta anônima, enviada por alguém

5 "Puis un jour, ses parents ont trouvé une lettre anonyme dans leur boîte aux lettres. Elle a été publiée intégralement dans le journal Pote à pote avec le témoignage de cette fille [...] Dans Pote à pote, elle a raconté qu'elle a alors décidé de s'enfuir de chez elle. Aujourd'hui, elle vit seule et n'a pratiquement plus aucun contact avec ses parents. Mais elle est entrée à la Comédie-Française et réussit à vivre de sa passion. Elle a quand même gagné" (GUÈNE, 2011, p. 108). 
da comunidade, alertando os pais sobre a conduta da filha, a qual estaria, segundo a carta, se afastando das normas de comportamento previstas na cultura de origem e denegrindo a reputação dos pais. Diante da pressão do grupo e do risco de perda de status na comunidade, os pais a impedem de sair de casa e participar de suas atividades no grupo de teatro. Desse modo, a vigilância do grupo se vê reforçada pelo disciplinamento da própria família.

Como Samra, também essa personagem modelo, distante do escopo de interações de Doria, não permite ser silenciada, procurando por outros espaços em que a vigilância social não a sufoque. Além desse distanciamento de um contexto social que não permite inovações, ela também alcança a independência financeira, ao transformar seu interesse pelo teatro em profissão. Ao entrar numa das mais importantes instituições da produção teatral da França, a ComédieFrançaise, ela também começa a participar da produção de sentidos que circulam naquela sociedade, representando por meio de sua voz a presença das minorias oriundas de fluxos migratórios, numa instituição de destaque nacional. Doria identifica em seu percurso identitário uma série de elementos que ela pode utilizar para imaginação de seu próprio futuro, com destaque ao investimento numa carreira profissional. 
Um outro elemento importante nessa identidade modelo reside na mobilização das mídias para sua narrativa. Samra também já tinha feito isso, ao anunciar o casamento no jornal. Neste último caso, a história publicada traz a carta que desencadeia a tentativa de silenciamento, acompanhada de sua história de sucesso na instituição cultural. É por meio dessa forma de disseminação que Doria chega a conhecer esse caminho de concretização existencial. Também neste caso, o conteúdo de identificação não reside na fuga, nem tanto no sucesso profissional, pois Doria não planeja fugir e seu êxito na escola é limitado. Contudo, ela identifica que tanto essa modelo, como também Samra, não deixa se abater pelas dificuldades, enfeixando forças para se distanciar de comportamentos herdados e trilhar um caminho de autonomia.

Em ambos os casos, o papel de modelo reside primeiramente na oferta de narrativas de identidade que conseguiram se distanciar dos modelos de gênero previstos na cultura da primeira socialização. No lugar da aceitação tácita, as duas personagens distantes rompem com a herança cultural e, de certo modo, adotam formas de concretização existencial vividas na cultura de assentamento ou de sua segunda socialização. Embora Doria não se encontre em 
nenhuma das situações vividas por essas personagens, ela depreende dessas narrativas a necessidade de questionar os modelos herdados e prestar atenção naquilo que tem importância no seu universo pessoal, a fim de instaurar sua própria voz.

As histórias de sucesso, apesar da perda do capital social oriundo da família, Ihe ensinam que é possível reconstruir esse capital de outras formas. A despeito da ausência de um impacto imediato, essas diferentes narrativas contribuem para a imaginação de alternativas para seu próprio futuro, fornecendo estratégias de organização de identidade que podem se transformar em chaves importantes para sua própria história. Ao verificar a semelhança no princípio das atribulações, ela encontra certo consolo e, sobretudo, motivação para ser agente da própria história.

\section{MODELOS PRÓXIMOS}

O segundo conjunto de modelos provém de personagens secundárias que circulam no entorno de Doria, em parte em contato mais próximo com a mãe, em parte numa interação mais intensa com Doria. Também aqui, todas as personagens-modelo são figuras femininas, apresentando algum elo com a história de fluxos migratórios. Semelhantemente àquilo que ocorreu com as personagens- 
modelo mais distantes, estas igualmente oferecem novas intepretações da realidade e, sobretudo, da condição da mulher, na intersecção entre a socialização da cultura de origem e sua ressocialização no novo contexto social. Este oferece formas diferentes de administrar o discurso sobre questões voltadas aos papéis de gênero, à distribuição de poder e agência e aos modos como identidades podem ser narradas nos diferentes contextos sociais. Por consequência, os modos como as negociações dessas narrativas são realizadas entre os diferentes atores sociais apresentam diferenças substanciais no que concerne à articulação de uma voz própria.

Dentre esses modelos, encontra-se a personagem chamada por Doria de tia Zohra, uma amiga bastante próxima da mãe e que passa por uma crise em sua família. Essa crise é desencadeada pelo envolvimento do filho em ações ilegais, o que acaba provocando sua prisão. Enquanto a mãe administra essa situação na França, o pai se encontra no seu país de origem, onde passa longos períodos, voltando periodicamente para a Europa. Ao conversar com a mãe de Doria, ela confessa seu medo de revelar ao marido os acontecimentos que envolvem o filho, por conta de sua possível reação: 
Por falar em tia Zohra, ela conseguiu reunir coragem pra contar tudo pro velho caduco do marido. Tiveram uma briga muito violenta quando ele soube o que tinha acontecido, e aquele velho gagá bateu na tia Zohra. Ele só parou porque não aguentava mais, tava com dor no braço e palpitação no coração. Aí, ele sentou, pediu um copo d'água pra ela, pra se refrescar. Ela foi pegar, e a coisa acabou por aí...

Ela contou tudo pra gente. Todo dia, ela reza pra Deus pra que ele volte pro lugar de onde ele vem. E eu penso que, ainda há pouco tempo, a mamãe rezava pra que o outro voltasse. (GUÈNE, 2006, p. 106)

Num primeiro momento, o tom jocoso, com o qual a voz narrativa relata os acontecimentos após a conversa com o marido, parece amenizar sua gravidade, mas, ao mesmo tempo, essa voz também revela que já não tem qualquer respeito por alguém que se utiliza da violência para resolver um problema de família. Além desse deslocamento nas lógicas de concessão de respeito, há um movimento afetivo, em que a voz narrativa enfeixa sua solidariedade e empatia em direção a essa mulher. Com isso, não somente afetos encontram um destino de investimento, estes estão

\footnotetext{
6 "A propos de Tante Zohra, elle a eu le courage de tout raconter au vieux fou, son mari. II y a eu une violente dispute entre eux quand il a appris ce qui s'était passé et ce vieux maboul a tapé sur Tante Zohra. Il s'est arrêté un moment parce qu'il en pouvait plus, il avait trop mal au bras et des palpitations au cœur. Alors il s'est assis et lui a demandé un verre d'eau pour se désaltérer. Elle est allée lui chercher à boire et ça s'est terminé comme ça... Elle nous a tout raconté. Chaque jour, elle prie Dieu pour qu'il retourne d'où il vient. Quand je pense qu'il y a encore quelque temps, Maman priait pour que l'autre revienne" (GUÈNE, 2011, p. 72-73).
} 
acompanhados de um trabalho cognitivo, com maior ou menor grau de consciência, que busca compreender os comportamentos arbitrários que impedem a narrativa autônoma dessa mulher. Nesse exercício de solidariedade, Doria aprende a administrar afetos, a identificar os valores que regem sua existência e a enxergar alternativas para narrativa de identidade, para além dos modelos herdados.

Ao lado desse exercício de afetividade, Doria também depreende do comportamento de sua tia Zohra o conhecimento de que é possível imaginar o futuro a partir de outros eixos, mais especificamente de que é possível concretizar sua existência, sem a presença de uma pessoa cuja prioridade é a vazão irracional do ódio e que ignora completamente a aflição da família. Doria não tarda em construir uma analogia com a situação na própria família, onde o pai tampouco hesita em priorizar seus próprios interesses, deixando os outros membros da família sem amparo. Ao participar indiretamente desse relato, compreendendo seu conteúdo e construindo sentidos, a protagonista traça vetores importantes para sua própria visão de mundo. Nisso, a identificação com a tia Zohra, de certa forma, a guia nos posicionamentos que vai adotando para sua própria concretização existencial. 
Uma segunda personagem-modelo, com a qual Doria tem uma interação muito mais direta, é Lila, atendente de supermercado e mãe de Sara. Divorciada e sem parentes próximos na capital francesa, Lila precisa de ajuda para cuidar da filha, Sara, e por isso contrata Doria como babá. Inicialmente o envolvimento está pautado pelo interesse na prestação de serviços, mas rapidamente se transforma num empenho afetivo mais amplo. A partir dessa visão afetivamente envolvida, a voz narrativa relata a história de Lila:

Aí, um dia, ela encheu o saco de piadas do sogro, da linguiça defumada do aperitivo e do marido diplomado desempregado que passava o tempo todo jogado no sofá assistindo a reprise do programa e bebendo cerveja. Foi quando ela pediu o divórcio, e não deve ter sido mole. Hoje, ela cria a filha sozinha, mas ainda tem esperança de encontrar alguém que lhe "corresponda" realmente. Isso me fez lembrar de um artigo sobre mães solteiras que li numa revista que tava dando sopa em cima da mesinha de um consultório médico. Bem, enfim, entendi que, por trás daquela aparência de caixa de supermercado que recorta foto de produto de moda da revista Mulher de Hoje, a Lila é uma grande sonhadora. (GUÈNE, 2006, p. 119$)^{7}$

7 "Et puis un jour, elle en a eu marre, des blagues du beau-père, du saucisson sec à l'apéro et de son mari chômeur attitré qui passait son temps enfoncé dans le canapé à mater des rediffusions à la télé en buvant une bière qui porte comme nom une date du milieu du XVII e siècle. Alors elle a demandé le divorce et ça a pas été facile. Aujourd'hui, elle élève sa fille toute seule mais elle espère encore rencontrer quelqu'un qui lui "correspond» vraiment. Ça m'a fait penser à un article sur les mères célibataires que j'avais lu dans un magazine qui traînait sur la 
Como no episódio de Samra, também Lila se envolve com um homem oriundo do grupo dominante, com o qual acaba se casando. Ao contrário de Samra, contudo, cuja família reprovava o relacionamento, neste caso, a reprovação provém da família do marido. O excerto relata acontecimentos de um estágio já mais avançado desse relacionamento. Desgastada com a falta de apoio e de um posicionamento claro por parte do marido, Lila opta por terminar esse envolvimento, ao pedir seu divórcio. Se Samra precisou organizar estratégias afetivas para processar e lutar por seu desejo de viver com um parceiro que não tinha a mesma origem cultural, Lila precisa enfeixar suas emoções, de modo a se decidir pelo divórcio e concretizar uma existência marcada por fragilização econômica e dificuldades práticas do dia a dia, dada a necessidade de criar a filha sozinha, sem o respaldo social da família ou de um círculo de amigos próximos. Em ambos os casos, a despeito da enorme fragilização emocional, as duas mulheres mostram resiliência e não renunciam àquilo que Ihes é importante. Nesse aspecto, reside um primeiro elemento de identificação, especialmente, na força de vontade e no potencial de agência que ambas demonstram diante de adversidades.

table basse chez le médecin. En tout cas, j'ai compris que derrière ses apparences de caissière de supermarché qui découpe des articles tendance dans Femme actuelle, Lila, c'est une grande rêveuse" (GUÈNE, 2011, p. 84). 
Um segundo elemento de identificação e, possivelmente, o mais importante, se solidifica na atitude de Lila diante do futuro. Apesar de um relacionamento fracassado e que a fragiliza em muitos sentidos, ela não deixa de acreditar no potencial da configuração afetiva inerente ao amor. Com isso, ela não renuncia à possibilidade de uma narrativa de identidade que inclui um envolvimento amoroso. Esse otimismo diante das aflições, com as quais se vê confrontada, é reforçado, quando Doria a caracteriza como sonhadora, ao final da citação. No lugar do silenciamento da imaginação do futuro, ela continua acreditando que há caminhos para a concretização de uma identidade em consonância com seus anseios.

Como em todas as outras situações, Doria toma conhecimento desses relatos e os interpreta de sua forma, criando os fundamentos para os elementos, com os quais se identifica. Do caso de Lila, além de enxergar a mulher forte e decidida a traçar o próprio caminho com autonomia, ela também vê o otimismo necessário para pré-dispor, de certo modo, o que pode acontecer no futuro. Sem essa imaginação de futuro, o potencial de inovação permanece bastante limitado. Essa atitude diante da existência parece inspirar Doria, pois apesar da situação na escola, na família, 
no contexto social, ela termina seu relato acreditando no potencial do futuro.

Esse futuro também contém uma dimensão de ação política, cujo modelo ela depreende de uma colega de trabalho da mãe, no terceiro e último exemplo a ser discutido aqui. Trata-se de Fatouma Konaré

Agora, as boas-novas. Dei com uma reportagem no Jornal regional do canal 3 outra noite, e, quem foi que eu vi, toda assanhada, vestindo um bubu-cor-de-rosa? Fatouma Konaré, a antiga colega da mamãe no motel de Bagnolet. O nome dela tava escrito embaixo da tela: "Delegada Sindical". O comentário dizia que as meninas tinham ganhado a luta. As reivindicações seriam atendidas logo. Até as empregadas que tinham sido demitidas durante o período de greve, ou aquelas que tivessem ido embora sem indenização, teriam reparações financeiras. Será que isso quer dizer que mamãe também vai ganhar uma grana, mesmo sem ser grevista? De repente, todos os meus pensamentos se dirigiram praquele babaca do seu Schacal. Ele deve ter quebrado a cara. Ha! Ha! Ha! Bem feito! (GUÈNE, 2006, p. 161-162) ${ }^{8}$

\footnotetext{
8 "Pour les bonnes nouvelles, je suis tombée sur un reportage du journal régional de France 3 l'autre soir et qui je vois à l'écran toute pimpante avec un boubou rose? Fatouma Konaré, l'ancienne collègue de ma mère au Formule 1 de Bagnolet. Y avait marqué son nom dans le reportage avec en dessous: «Déléguée syndicale». Le commentaire disait que les filles avaient gagné la lutte. Leurs revendications seraient entendues prochainement. Même les salariés qui ont été licenciés pendant la période de grève ou ceux qui sont partis sans indemnisations verront ces préjudices réparés. Ça veut dire aussi que Maman va toucher des sous, même si elle était pas gréviste? D'un coup, toutes mes pensées sont allées vers ce gros con de M. Schihont. II a dû bien se faire gratter. Ha Ha Ha! Bien fait!" (GUÈNE, 2011, p. 114).
} 
Ao contrário da figura materna, ela apresenta uma estrutura familiar e, com isso, o capital social que lhe permite arriscar o emprego, ao questionar as decisões arbitrárias do chefe do motel, seu Schacal. No lugar de permitir que seja silenciada e concordar tacitamente com todas as imposições do lugar de trabalho, ela começa a assumir responsabilidade pelo espaço social, reclamando a agência de suas ações para si. Nisso, há uma mudança no modo de percepção, pois ela deixa de guiar seu olhar em direção à conformação da visão de mundo do chefe, para instaurar modos diferentes de se apropriar da realidade e formar sentidos. Com efeito, ela passa a pensar o espaço social de forma autônoma, revendo a distribuição de recursos, a igualdade social, os direitos básicos. Como nos outros exemplos, nos quais as personagens femininas se apropriam da comunicação midiática para manifestar sua voz e, indiretamente, contribuir para a construção do imaginário nacional, onde mulheres com histórico de imigração expressam suas visões de mundo, também neste caso a personagem Fatouma Konaré passa a integrar essa paisagem.

Com base nos movimentos sindicalistas da amiga da mãe, Doria é inspirada a pensar sobre as condições de trabalho de mulheres, especialmente daquelas numa situação social 
fragilizada. Ao ver a reportagem, ela constrói o nexo entre as reivindicações articuladas pelo grupo liderado por Fatouma Konaré e as condições de trabalho da mãe, cujo desesperança e cujo medo testemunha diariamente. Esse exercício de percepção social certamente não a transforma numa ativista política, mas contribui para a revisão de visões de mundo e para o reposicionamento de atores sociais pertencentes a grupos minoritários, às margens daquela sociedade.

\section{CONSIDERAÇÕES FINAIS}

Ao final do romance, a jovem protagonista conseguiu resolver uma série de desafios, os quais, com frequência, teriam sido responsáveis pelo fracasso de integração social para muitos atores sociais oriundos de contextos de fluxos migratórios. Assim, apesar de suas dificuldades na escola, ela consegue encontrar o caminho para um curso profissionalizante. Apesar da fragilidade social vivida em casa, ela desenvolve a estabilidade afetiva que lhe permite apoiar a mãe e, inclusive, iniciar um relacionamento amoroso. Ao final do romance, no tom jocoso e subversivo que caracteriza a voz narrativa, Doria quer "encabeçar a revolta do Conjunto Paraíso" (GUÈNE, 2006, p. 175)․ Ao longo da narrativa ocorre uma transformação substancial: a

9 "mènerai la révolte de la cité du Paradis" (GUÈNE, 2011, p. 122). 
voz desesperançada que inicia o texto passa a ser uma voz otimista, que volta a imaginar o amanhã.

Nisso, as diferentes personagens-modelo, próximas ou distantes, tiveram um impacto. Em todas as situações que elas representam e que são relatadas pela protagonista, esta depreende conhecimentos que ela integra, direta ou indiretamente, em sua narrativa de identidade. São os diferentes exemplos de superação e de reformulação do papel da mulher na intersecção com a imigração que lhe permitem dar início a uma tessitura que imagina um outro espaço social. Nesse potencial de desencadear processos criativos de imaginação reside a mais importante contribuição dessas personagens para a apropriação de realidade da protagonista. Com isso, a voz de Doria se junta a um coro de outras personagens femininas que se destacam pelo "espírito criativo".

\section{REFERÊNCIAS}

AHONEN, Mirka. Redefining stereotypes: The banlieue and female experience in Faïza Guène's Kiffe kiffe demain. French Cultural Studies, v. 27, n. 2, p. 168-177, 2016.

ALBERT, Christiane. L'immigration dans le roman francofone contemporain. Paris: Éditions Karthala, 2005.

CARREIRA, Shirley de Souza Gomes. Em nome da mãe: uma reflexão sobre a representação do gênero em obras da literatura contemporânea. Vertentes (UFSJ), v. 36, p. 46-61, 2010.

CROSS, Susan E.; MADSON, Laura. Models of the Self: Self-Construals and Gender. Psychological Bulletin, v, 122, n. 1, p. 5-37, 1997. 
GUÈNE, Faïza. Amanhã, numa boa. Tradução de Luciana Persice Nogueira. Rio de Janeiro: Nova Fronteira, 2006.

GUÈNE, Faïza. Kiffe, kiffe demain. Paris: Hachette, 2011.

HARGREAVES, Alec G. Perceptions of Ethnic Difference in Post-War France. In: IRELAND, Susan; PROULX, Patrice J. (Ed.). Immigrant Narratives in Contemporary France. London: Greenwood Press, p. 7-22, 2001.

HARGREAVES, Alec G. Traces littéraires des minorités postcoloniales en France. Mouvements HS 1, p. 36-44, 2011.

HERMANNS, Hubert J. M., The Dialogical Self: Toward a Theory of Personal and Cultural Positioning. Culture \& Psychology, v. 7, n. 3, p. 243-281, 2001. KEUPP, Heiner et al. Identitätskonstruktionen. Das Patchwork der Identitäten in der Spätmoderne. Reinbek bei Hamburg: Rowohlt, 2002. MATHIAS, Dionei. Imigração e resistência. Revista Estudos Feministas, v. 28, n.1, p. 1-10, 2020a.

MATHIAS, Dionei. Pertencimento e afetividade em Amanhã, numa boa, de Faïza Guène. Signótica, v. 32: e59853, 2020b.

MELO, Flávio García Queiroz de; CARREIRA, Shirley de Souza Gomes. Deslocamentos espaciais ou culturais e sua representação ficcional. Caderno Seminal Digital, v. 32, p. 1-4, 2019.

RAPUCCI, Cleide Antonia. In search of gardens and clay. Creativity and displacement in the African diaspora. In: MATOS, Mário; PAISANA, Joanne; ESTEVES PEREIRA, Margarida (Org.). Transcultural Amnesia. Mapping Displaced Memories. Amnésia transcultural. Para uma cartografia de memórias deslocalizadas. Vila Nova de Famalicão: Humus, p. 125-133, 2016.

\section{Dionei Mathias}

Doutor em Letras pela Universität Hamburg e pela Universidade Federal do Paraná.

Professor da UFSM.

E-mail:dioneimathias@gmail.com

Lattes: http://lattes.cnpq.br/0718781986349346

Orcid iD: https://orcid.org/0000-0001-8415-1460 